com muita vontade de levar adiante o meu trabalho de tese.

Ela foi uma orientadora, amiga, transparente, doce, sem perder a firmeza e a profundidade teórica até os seus últimos dias de vida. Sinto saudades!
Ana Lucia Artioli é psicóloga, doutoranda em Psicologia Social. Professora Assistente do Departamento de Pedagogia da Universidade do Estado de Mato Grosso (UNEMAT). Endereço para correspondência: Avenida São João, s/n, Cavalhada, Cárceres, MT, 78200-0000. pedagogia_cac@unemat.br

\title{
O AMOR PELA DOCÊNCIA E PELA PESQUISA, SENTIMENTO MAIOR QUE O SOFRIMENTO FÍSICO
}

\author{
Célia Maria Marcondes Ferraz \\ Escola Superior de Propaganda e Marketing de São Paulo, São Paulo, Brasil
}

(Depoimento apresentado em 29 de maio de 2006, numa homenagem à Sílvia Lane)

A Sílvia gostava de pedir a um dos alunos do Núcleo que exercesse o papel de secretário ou de secretária. Era alguém que organizava com ela as atividades, informava aos demais colegas sobre a programação e a cada semana lembrava a todos sobre o que ira acontecer: aulas, leituras ou encontros com outros núcleos.

Até o final de 2005 era Ana Lúcia Artioli a secretária e neste ano, 2006, eu fui escolhida pelo grupo para exercer este papel. E, em virtude das circunstâncias, esta atividade singelamente burocrática me aproximou mais da Sílvia. Nós nos falávamos todas as semanas. E é nesta condição, de secretária do Núcleo que vou relatar a vocês os últimos dias da agenda de trabalho da Sílvia, mostrando quais eram as sua preocupações em relação à Pontifícia Universidade Católica (PUC) e aos alunos. O meu relato segue o formato da agenda. Cada vez que nos falávamos havia uma espécie de minuta que eu distribuía aos colegas e que divido agora com vocês.

Dia 31 de janeiro de 2006: Sílvia, como vai? Estou me apresentando ao trabalho.

Resposta: Não estou nada bem. Passei muito mal nas férias. Estômago. Uma dor terrível e não consigo comer nada. Mas o que está me preocupando muito é a crise na PUC. A Fundação assumiu a coordenação do processo de demissões. É preciso reduzir drasticamente as despesas e vão começar a demitir em massa. É uma interferência na autonomia da reitoria além de um processo de destruição de saber, de competência e de agravamento da precariedade das condições de trabalho dos docentes, e por conseqüência, dos alunos. Vocês têm que estar inteirados do que se passa. O início das aulas foi adiado para março, mas vocês devem se reunir, ir a PUC e defender uma posição.

Dia 13 de fevereiro: Sílvia, está melhor?

Resposta: Não. Continuo muito mal. Marquei consulta com um gastro muito bem recomendado. Espero que agora dê certo. Você se comunicou com o grupo?

Célia: Sim. Vamos nos encontrar, algumas pessoas hoje à tarde na PUC para nos inteirarmos dos fatos. $\mathrm{O}$ que você gostaria que fizéssemos?

Sílvia: Vai haver uma reunião do programa. Vocês deveriam participar. É preciso neste momento acompanhar todos os passos, todas as decisões. Pode ser até mesmo que do ponto de vista prático, não haja nada que possamos fazer. Mas precisamos deixar claro o nosso protesto. A PUC teve e tem uma importância enorme na formação dos quadros docentes de todas as Universidades brasileiras. Eu não me conformo que este esforço todo não seja levado em consideração num momento que a PUC precisa de ajuda para pagar os bancos. Aguardo as suas impressões sobre o que virem nesta tarde.

Dia 06 de março: segunda feira: Sílvia, como passou o carnaval?

Resposta: Mal. Não consegui nem mesmo chegar até o jardim de tão mal que passei. Não posso comer nada e meu estômago dói demais. Já estou com exames marcados. Todos os ultra e as cópias que você pode imaginar. Vamos ver se consigo agora descobrir o que eu tenho para me tratar e retomar a minha vida normal. Vou tentar ir nesta quarta-feira para receber os novos alunos. Te- 
mos dois novos colegas: Daniel e Noeli que precisamos acolher no Núcleo.

Dia 08 de março: quarta feira: Primeiro dia de aula. Fui chamada pela Sílvia ao telefone do programa, já na PUC:

Sílvia: Célia, não vai dar para ir. Marcaram um exame para hoje à tarde. Mas eu quero que vocês acolham os novos alunos por mim. Expliquem o que fazemos, como conduzimos as nossas reuniões. E não deixem de explicar para eles a crise da PUC. Não deixem que eles pensem que somos uma universidade irresponsável que gasta mais do que arrecada. Expliquem que esta crise vem de longe e que sempre valorizamos a excelência dos docentes, a qualidade do ensino e tivemos isto como uma prioridade. Expliquem a eles a arbitrariedade do processo.

Dia 14 de março: Terça feira à tarde: Toca o meu telefone.

Sílvia: Oi Célia, estava procurando por você. Recebeu meu recado? Eu queria nesta semana reunir o grupo aqui em casa, mas amanhã é o dia da reunião de recepção dos novos alunos do programa convocada por Mary Jane. Vocês não devem faltar. Já falei com Maria Helena e quero que ela me represente, que fale em meu nome se necessário for. Com isto eu tenho uma semana para os remédios fazerem efeito. Você sabe que a endoscopia não deu nada?

Dia 21 de março parte da tarde. Toca o meu telefone.

Sílvia: Célia? Vamos ver se conseguimos amanhã reunir o núcleo aqui em casa. Você pode organizar? Estou preocupada com os novos alunos e quero fazer uma chamada geral: Ana Lúcia esta em contato comigo. Rogério e Dirce também. Rose, que está com data marcada para depositar, tem falado comigo o tempo todo, mas Adjuto e Esther ainda não me procuraram. Vou ver se converso com todos e falamos sobre a programação 2006.

Dia 22 de março: quarta feira, dez horas da manhã. Toca o meu celular.

Sílvia: Célia? Não vai dar para receber vocês. Estou muito mal. Vomitei a noite toda e mal consigo parar em pé. Mas será que você poderia passar aqui, pois eu vou definir a programação de 2006 e há recados diversos para o grupo. Sim? Ótimo eu te espero.

Por volta de 13.30h saí com a definição de que o Significado Histórico da Crise na Psicologia de Vigotsky seria o primeiro tema, e o recado para que todos ligas- sem para falar com ela sobre os seus respectivos projetos, incluindo os novos alunos.

Dia 30 de março, quinta feira, pela manhã: Sílvia? Estamos lendo o texto. É complexo e o tempo todo nós tendemos a ir para o décimo quarto capítulo. A Yara sugeriu que lêssemos um outro autor que interpreta Vigotsky para facilitar o trabalho. O que você acha?

Sílvia: Eu acho que vocês devem continuar. O texto é difícil, mas por meio dele fica claro como Vigotsky construía a sua crítica. E isto dá uma visão clara do método Vigotsky. Na próxima semana estarei com vocês e vamos esclarecer tudo.

Dia 05 de Abril, quarta feira, onze horas da manhã: Toca meu telefone.

Sílvia: Célia? Hoje eu vou. A Lílian já esta de plantão para me levar. Estou com saudades de todos. Apenas o Adjuto ainda não falou comigo. Veja se você consegue localizá-lo, pois apesar de saber da competência dele, fico preocupada com o trabalho. E, a propósito, como vai o seu, acha que está atrasado?

Mas nossa querida professora não veio. Chegou até a metade do caminho e teve que retornar. Estávamos todos na sala de aula quando recebemos um recado da Marlene. (secretária do programa).

Dia 11 de abril terça feira, pela manhã: Eu ligo para a professora.

Sílvia: Célia eu já não sei mais o que eu faço. Por enquanto não deu nada. E eu não melhoro. A Maria Helena acha que eu estou somatizando em função da crise da PUC. E eu estou mesmo muito brava com tudo isto. Acho que não é o momento de radicalizar posições, uns com os outros. Creio que é necessária também, uma articulação com Brasília. O governo federal não pode esquecer da importância da PUC para o ensino no Brasil. Eles ajudam tantas empresas em dificuldades em nome da utilidade pública, porque não ajudar a PUC? Eu quero recomendar para vocês a leitura de um artigo meu, um bem pequeno que acho que vai ajudar a esclarecer o Vigotsky: Por uma epistemologia da subjetividade. Se você não tiver, tenho certeza que a Yara tem. Ou talvez até mesmo a Marlene, a secretária do programa, tenha o livro. Leiam. Amanhã à tarde e eu vou fazer o impossível para estar com vocês.

Dia 12 de Abril. 14.30h da tarde. Na porta do programa Marlene, a secretária, me chama: "Sílvia quer falar com você." 
Sílvia: Célia? Não vai dar. Voltei novamente da metade do caminho.

Sílvia saiu de casa, novamente, tentando reunir-se com o Núcleo, mas não suportou a dor no estômago e retornou do meio do caminho. Nós havíamos ligado para ela da PUC e o seu telefone não respondia. A Rose esteve com ela para assinar a tese e ficou impressionada com o seu estado. Mas ficamos felizes porque ela disse que viria. Mas ela já estava muito doente e passou mal no meio do caminho, tendo que voltar para casa.

Nesta noite, ao telefone ela me dizia: os exames mostraram umas manchas no fígado e eu tenho que procurar um outro especialista. Continuo com fortes dores no estômago e vomitando.

Dia 19 de abril, pela manhã, como de hábito: Meu telefone toca.

Sílvia: Célia, eu de novo. Hoje eu vou fazer uma ressonância magnética para olhar o que são as manchas. O médico está com medo que seja câncer. E o texto ajudou?

Falei com Noeli sobre a descrição do Núcleo que a secretaria pediu para a [Coordenação de Aperfeiçoamento de Pessoal de Nível Superior] CAPES. Não esqueçam de incluir a continuação da pesquisa com os índios. Quero agora continuar com o estudo dos sonhos dos índios. A Maria Helena sabe perfeitamente o que eu quero, falem com ela.

Dia 22 de abril: sábado, em casa da Sílvia: Célia, Maria Helena e Marlito, três alunos, que decidiram fazer uma visita. Palavras finais da Sílvia já com o diagnóstico de câncer no pâncreas e a internação marcada para segunda feira: Célia, diga ao grupo que vou ficar fora uns trinta dias. Seria interessante que vocês se juntassem ao núcleo da Bader, para ler o Vigotsky, e que todos os orientandos procurassem a Maria do Carmo, no caso de dúvidas sobre os seus respectivos projetos. Aliás, a Ana Lúcia já está falando com ela direto. Liguei para a Maria do Carmo, mas acho que, em virtude do feriado, ela esta viajando, não estou conseguindo encontrá-la. A Dirce, no momento, é a minha maior preocupação porque tem que depositar a tese e nós não olhamos as conclusões. Vocês sabem que eu não consigo mais ler na tela? Ela me trouxe o texto escrito e vou levar comigo para o hospital. Mas a Maria do Carmo vai me dar uma força. E, dona Célia, daqui a trinta dias eu quero ver sua dissertação escrita.
Dia 24 de abril. Nove horas da manhã do Hospital Sírio Libanês: Toca o meu telefone: Célia? É Yara sua colega do Núcleo. Eu estou com Sílvia no hospital. Escuta, a Sílvia está aqui ao meu lado e te pede um favor: descobre os telefones da Maria do Carmo na PUC, pois ela não conseguiu encontrar Maria do Carmo este final de semana em casa. A Sílvia precisa falar sobre a Dirce. Trouxe o texto da tese, mas não consegue ler. Acho que ela está muito fraca.

Célia: OK. Eu vou ligar agora mesmo, mas fala para a Sílvia descansar que ela esta num hospital para se tratar. Eu mesma vou falar com Dirce se for necessário e explicar tudo. Todos queremos dar a Sílvia um pouco de sossego.

Dia 28 de abril: Sílvia é levada para a unidade semiintensiva coronariana. Esther, outra aluna, que esteve com ela neste mesmo dia me contou que já meio inconsciente, o médico lhe perguntou: E então dona Sílvia, a senhora esta com alguma dor?

Sílvia: Dor propriamente não. Um desconforto e uma enorme fraqueza. Disse ela num timbre de voz que continha a autoridade de alguém que esta habituada a traduzir sentimentos em conceitos. "Ela não perde a majestade dizia a Esther".

Dia 29 de abril, tarde da noite: Morre a Professora Sílvia Lane. Ao seu lado junto da família, uma aluna de muitos anos, a Yara, convidada pelos filhos para velar os últimos momentos da Professora Sílvia Lane.

E assim a Sílvia foi professora até o momento de sua morte. A Yara Araújo estava lá representando todos nós, todos os alunos que por muitos anos aprenderam com Sílvia na PUC, ou que por meio dos seus livros esclareceram as suas dúvidas, e conheceram mais sobre o ser humano em toda a sua esplendida complexidade. À Professora Sílvia Lane nossa eterna homenagem.

Célia Maria Marcondes Ferraz é mestranda em Psicologia Social pela PUC/SP e Professora da Escola Superior de Propaganda e Marketing de São Paulo. Endereço para correspondência: Rua Joaquim Távora 1240, $2^{\circ}$ andar, Vila Mariana, São Paulo, SP, 04015-013 cferraz@espm.br

Recebido: 24/05/2007

Aceite: 14/09/2007

$1^{a}$ revisão: 30/07/2007 